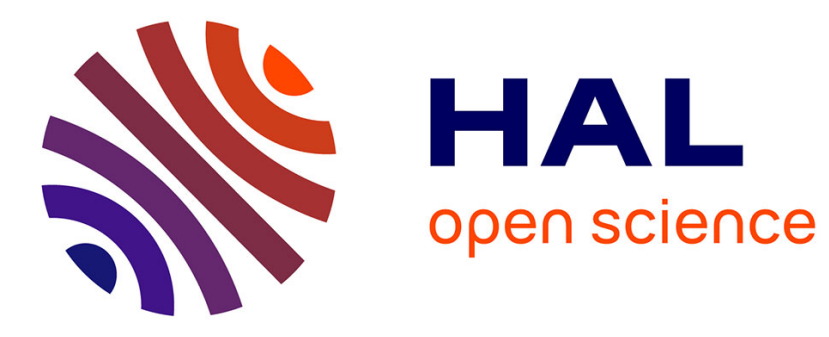

\title{
Soybean is less impacted by water stress using Bradyrhizobium japonicum and thuricin-17 from Bacillus thuringiensis
}

Marion Prudent, Christophe Salon, Alfred Souleimanov, R. J. Neil Emery, Donald L. Smith

\section{To cite this version:}

Marion Prudent, Christophe Salon, Alfred Souleimanov, R. J. Neil Emery, Donald L. Smith. Soybean is less impacted by water stress using Bradyrhizobium japonicum and thuricin- 17 from Bacillus thuringiensis. Agronomy for Sustainable Development, 2015, 35 (2), pp.749-757. 10.1007/s13593014-0256-z . hal-01284278

\section{HAL Id: hal-01284278 \\ https://hal.science/hal-01284278}

Submitted on 7 Mar 2016

HAL is a multi-disciplinary open access archive for the deposit and dissemination of scientific research documents, whether they are published or not. The documents may come from teaching and research institutions in France or abroad, or from public or private research centers.
L'archive ouverte pluridisciplinaire HAL, est destinée au dépôt et à la diffusion de documents scientifiques de niveau recherche, publiés ou non, émanant des établissements d'enseignement et de recherche français ou étrangers, des laboratoires publics ou privés. 


\title{
Soybean is less impacted by water stress using Bradyrhizobium japonicum and thuricin-17 from Bacillus thuringiensis
}

\author{
Marion Prudent • Christophe Salon • \\ Alfred Souleimanov • R. J. Neil Emery • Donald L. Smith
}

Accepted: 15 September 2014 / Published online: 3 October 2014

(C) INRA and Springer-Verlag France 2014

\begin{abstract}
Climate change is forecasted to induce more drought stress events. Water scarcity is already the most limiting abiotic stress for crop production. With higher food demand, there is a need for sustainable solutions to cope with the loss of productivity due to water stress. It is known that plant growth-promoting rhizobacteria (PGPR) can colonize plant roots and increase plant growth. However, there is actually no sustainable method to decrease the impact of water stress. Therefore, we hypothesized that an application of thuricin-17, a molecule produced by the PGPR Bacillus thuringiensis, could enhance soybean tolerance to water stress. We grew soybean plants for 1 month in growth chambers in order to evaluate their response to thuricin-17 root application under drought, in association with the inoculation of $\mathrm{N}_{2}$-fixing Bradyrhizobium japonicum. We measured traits reflecting root architecture: number of tips, root diameter, root length, number of nodules; water fluxes: water potential, stomatal conductance; carbon nutrition: leaf area, photosynthetic rate, biomass and carbon partitioning; nitrogen nutrition: nitrogen partitioning and hormone signalling: abscisic acid concentration during the vegetative growth period. Our results show that thuricin-17 application under water stress increased plant biomass by $17 \%$, thus masking drought impact. This effect is due to modifications of below-ground
\end{abstract}

M. Prudent $(\bowtie) \cdot$ C. Salon

INRA, UMR1347 Agroécologie, BP86510, F-21000 Dijon, France

e-mail: Marion.Prudent@dijon.inra.fr

A. Souleimanov $\cdot$ D. L. Smith

Plant Science Department, McGill University, McDonald Campus,

21111 Lakeshore Road, St Anne de Bellevue, Quebec H9X 3V9, Canada

R. J. N. Emery

Department of Biology, Trent University, Peterborough, ON K9J

7B8, Canada structures, with $37 \%$ increase of root and $55 \%$ increase of nodule biomass, and to slight increases of leaf area and photosynthetic rate. We also observed that application of thuricin17 induced a $30 \%$ increase of root abscisic acid, an increase of root length and of leaf water potential. Finally, thuricin-17 induced an activation of nodule formation by $40 \%$, a partial restoration of nodule-specific activity, nodule growth and consequently, an increase by $17 \%$ of the total nitrogen amount in the plant. Overall, our findings reveal a new method to decrease the negative impact of water stress. Results also demonstrate that the plant restored an adequate water and $\mathrm{N}$ balance by changing its root structure.

Keywords Abscisic acid · Agroecology · Drought . Glycine max $\cdot \mathrm{N}_{2}$-fixation $\cdot$ Nodules $\cdot$ PGPR $\cdot$ Root growth

\section{Introduction}

Climate change is presenting major challenges to agriculture at a time when increasing world population is putting more pressure on global food supplies (Vadez et al. 2011). Climate change will result in increased drought stress and water scarcity is already the abiotic stress most limiting to crop production (Wallace 2000), and this is particularly pertinent to the drought-sensitive legumes (Liu et al. 2005). For example, a moderate level of water deficit can reduce soybean production by approximately $40 \%$ (Manavalan et al. 2009), thus limiting the production of soybean vegetable oil, protein feed or biodiesel (Friedman and Brandon 2001).

The agro-ecological advantages of legumes in cropping systems are clear, as they naturally enrich soil with nitrogen, due to their ability to establish atmospheric $\mathrm{N}_{2}$-fixing symbioses with rhizobia, within specific plant organs, the root nodules. This biological process leads to a major reduction in nitrogen fertilizer 
additions, and significantly reduces pollution linked to nitrogen fertilizer synthesis, transport and spreading (Avice et al. 2011). It also reduces ground water pollution with nitrate and emissions of the greenhouse gas nitrous oxide (Easterling et al. 2007). Water stress negatively inhibits nodule formation and symbiotic $\mathrm{N}_{2}$ fixation, by decreasing nodule size and by reducing nodule-specific activity (King and Purcell 2001; Serraj et al. 1999; Streeter 2003). Below-ground soybean responses to water stress consist in developing a longer taproot to reach the deeper available water and a greater number of lateral roots, leading to a more voluminous root system (Manavalan et al. 2009). Despite these advantages, in legumes, nodules are strong sinks for assimilates within the plant that compete for carbon assimilates both with the shoot and the roots (Schuize et al. 1999), indicating that it is necessary to consider the plant, as a whole, if we want to understand plant acclimation to stress conditions.

In response to drought, the plant hormone abscisic acid (ABA) is dramatically synthesized and plays a key role in closing stomata (see Acharya and Assmann (2009) for review), and regulating aquaporins either via their gene expression or via post-translational regulations. This leads to the regulation of water fluxes within the plant and impacts the absorption of nutriments. Accordingly, as water stress influences plant nutrition, the establishment of plant organs, their growth as well as their functions, there is a need to find alternative methods which could enhance plant tolerance to water stress. Under non-stressful conditions, plant growth-promoting rhizobacteria (PGPR) have been shown to enhance plant production, as they can colonize plant roots and increase plant growth through a wide range of mechanisms, including the modification of phytohormone synthesis (indole-3-acetic acid, cytokinins, ethylene, ABA, for review, see Dodd et al. (2010)), the reduction of heavy metal toxicity, or the suppression of disease by antibiosis (Whipps 2001). The PGPR Bacillus thuringiensis NEB17, isolated from soybean nodules (Bai et al. 2002), was shown to produce a bacteriocin named thuricin-17 (Gray et al. 2006) which stimulates the growth of both $\mathrm{C} 3$ dicot and $\mathrm{C} 4$ monocot plants (soybean and corn, respectively) (Lee et al. 2009). In addition, it has been suggested that PGPR could act as "biofertilizers" for helping plants tolerate abiotic stresses such as drought or salinity (Yang et al. 2009). PGPR can also induce a reproductive delay leading to a better tolerance of Arabidopsis to drought (Bresson et al. 2013). The objective of this study is thus to investigate whether an application of thuricin17 , in association with the inoculation of $\mathrm{N}_{2}$-fixing rhizobacteria Bradyrhizobium japonicum, could enhance soybean tolerance to water stress conditions during an early stage of development, which is the vegetative period.

\section{Materials and methods}

\subsection{Plant growth conditions and treatments}

Soybean (Glycine max L. Merr. cv. OAC Champion) seeds were surface-sterilized with $2 \%$ sodium hypochlorite for $5 \mathrm{~min}$ and thoroughly washed with distillated water. Soaked seeds were sown in plastic pots ( $13 \mathrm{~cm}$ diameter) containing vermiculite (Holiday ${ }^{\circledR}$, Montreal) and inoculated with $1 \mathrm{~mL}$ of a fresh solution of Bradyrhizobium japonicum strain 532C, which had been grown at $28{ }^{\circ} \mathrm{C}$ in yeast mannitol medium (YEM) to a cell density adjusted to $10^{8}$ cells per milliliter. Plants were grown in a growth chamber (Fig. 1a) under a 16-h photoperiod, $300 \mu \mathrm{E} \mathrm{m}^{-2} \mathrm{~s}^{-1}$ and $80 \%$ relative humidity at 26-22 ${ }^{\circ} \mathrm{C}$ (day-night temperatures). During the whole experiment, water and nutrient supplies were separately adjusted in order to feed all the plants with the same nutrient quantity. All the plants were watered three times a week with $20 \mathrm{~mL}$ of nitrogen-free double strength Hoagland's solution.

Of the 181 experimental units (plants in pots), 73 were randomly chosen to be well-watered while the remaining 108 were subjected to a water stress treatment starting when the plants reached vegetative cotyledon stage, corresponding to 7 days after seeding (DAS). Soil water capacity was determined by weighing pots filled with vermiculite: $100 \%$ of soil water capacity was obtained by weighing pots after having watered them in excess, and letting them drain overnight. Well-watered pots were watered daily with distillated water to keep them at no less than $90 \%$ of soil water capacity, while for the water-stressed pots, water was withheld until they reached $45 \%$ of soil water capacity, and kept at this moisture level until the end of the experiment.

Among the water-stressed experimental units, 54 randomly chosen pots were treated with $10^{-9} \mathrm{M}$ of thuricin-17, extracted and purified as explained in Lee et al. (2009). The treatment was applied beginning at the vegetative cotyledon stage by adding $10^{-9} \mathrm{M}$ of thuricin- 17 to the $20 \mathrm{~mL}$ of the $\mathrm{N}$-free Hoagland's solution.

\subsection{Sampling and measurements}

For each treatment, at the vegetative cotyledon stage, the first trifoliate stage (corresponding to 5 days after treatment), second trifoliate stage (corresponding to 10 days after treatment) and third trifoliate stage (corresponding to 16 days after treatment, see Fig. 1b), data were collected on 10 plants for plant height, leaf greenness (SPAD-502, Minolta, Japan), photosynthesis, stomatal conductance (LI-COR 6400 Inc, Lincoln, NE, 
Fig. 1 Pictures of a the growth chamber where soybean plants were grown and $\mathbf{b}$ a soybean plant at the third trifoliate stage

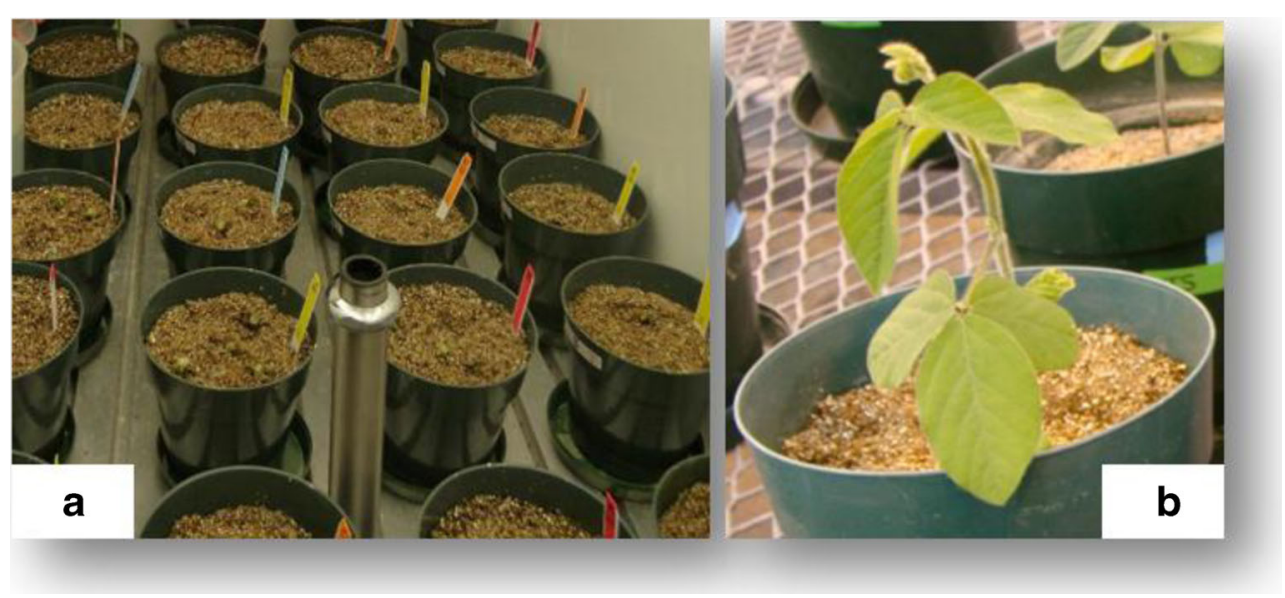

USA), and leaf water potential (WP4 potentiometer, Decagon, Washington, USA). Each plant was separated into four plant components: leaves, stem, roots and nodules. Leaf area and root architectural traits (number of nodules, root total length, root average diameter, number of tips) were recorded using the WinRHIZO software version 3.2, (Regent instruments Inc., Quebec, Canada). Collected tissues were dried in an oven set at $80{ }^{\circ} \mathrm{C}$ for 5 days, the dry weights (DW) were collected and samples ground before conducting duplicate carbon and nitrogen analyses on each plant using an elemental analyzer (Thermo Electron NC2500, Courtaboeuf, France). The specific activity of nodules for $\mathrm{N}_{2}$ fixation $\left(\varepsilon\right.$, in gN $\left.\left[\text { g.nodDWd }{ }^{-1}\right]^{-1}\right)$ ) between date $t_{\mathrm{a}}$ and date $t_{\mathrm{b}}$ was calculated as the ratio between the quantity of fixed $\mathrm{N}_{2}\left(\right.$ fix $N_{\mathrm{a} \rightarrow \mathrm{b}}$ ) and the integrated nodule dry weight ( $\left(\mathrm{DW}_{\text {nod }}\right)$ between $t_{\mathrm{a}}$ and $t_{\mathrm{b}}$ :

$\varepsilon=\frac{\operatorname{fix} N_{\mathrm{a} \rightarrow \mathrm{b}}}{\int_{\mathrm{a}}^{\mathrm{b}} \mathrm{DW}_{\text {nod }} \cdot d t}$

Six to nine other plants per treatment and developmental stage were harvested and divided into three biological pools. Their roots, nodules and leaves were separated, frozen into liquid nitrogen, freeze-dried and stored at $-80{ }^{\circ} \mathrm{C}$ before hormone extraction.

\subsection{Abscisic acid extraction, purification and quantification}

The freeze-dried tissue for ABA analysis was extracted, purified and quantified by an isotope dilution assay using extraction methods as adapted from Ross et al. (2004). During extraction, $\left[{ }^{2} \mathrm{H}_{4}\right] \mathrm{ABA}$ (NRC-PBI, Saskatoon, Canada) was added as quantitative internal standard. Purification included mixed mode reverse-phase/cation-exchange Oasis MCX-SPE column (Waters, Mississauga, Canada), pre-conditioned with $5 \mathrm{~mL}$ of $\mathrm{CH}_{3} \mathrm{OH}$ followed by $5 \mathrm{~mL}$ of $1.0 \mathrm{M} \mathrm{HCOOH}$. The sample was loaded in $1.0 \mathrm{M} \mathrm{HCOOH}$ and ABA was eluted with $5 \mathrm{~mL}$ of $\mathrm{CH}_{3} \mathrm{OH}$. Purified ABA were was analyzed by
(LC-(+)ESI-MS/MS) using a Dionex Ultimate 3000 HPLC system (Dionex, Bannockburn, IL, USA) coupled to a QTRAP 5500 triple quadrupole hybrid ion trap mass spectrometer (MDS Sciex, Concord, Ontario, CA) equipped with a turbo $\mathrm{V}$-spray source in negative ion mode. ABA was quantified by multiple reaction monitoring (MRM) of the mother (parent) ion and daughter (product) ions.

\subsection{Statistical analyses}

Statistical analyses were performed using the XLSTAT software, version 2010.5.02 (http://www.xlstat.com). For all variables, except $\mathrm{ABA}$ concentrations, differences among treatments were tested using the ANOVA-protected least significant difference (LSD) test. For ABA concentrations, as the number of replicates was equal to three, we tested differences among treatments with the Kruskal-Wallis non-parametric test. Only differences significant at $P<0.05$ were considered.

\section{Results and discussion}

Plant growth-promoting rhizobacteria can enhance plant fitness components via a large range of mechanisms leading to modifications of particular plant functional traits, either by conferring a biochemical potential or by modifying plant pathways (Friesen et al. 2011; Goh et al. 2013). The present work was initiated to assess whether the application of thuricin-17-a molecule synthesized by PGPR Bacillus thuringiensis strain NEB17-could enhance soybean vegetative development and $\mathrm{C}$ and $\mathrm{N}$ acquisition under a continuous water stress, when $\mathrm{N}$ furniture to the plant was only based on $\mathrm{N}_{2}$ fixation, meaning in symbiotic association with Bradyrhizobium japonicum. In order to test this hypothesis, (i) the establishment of plant aerial and below-ground organs and (ii) their functions related to carbon metabolism and nitrogen acquisition, were analysed throughout plant 
vegetative development. Experiments were conducted in order to study the effects of thuricin-17 application on the vegetative development of $\mathrm{N}_{2}$-fixing soybean plants, grown under water stress conditions. Plant traits were monitored for 16 days after water stress imposition by water withholding, in combination or not, with thuricin-17 application.

\subsection{Thuricin-17 alleviated the loss of biomass due to water} stress conditions by strongly increasing the below-ground structures

The effect of water stress on shoot biomass and plant leaf area was detectable by 10 days after the beginning of the treatment and became greater as plant development advanced, reaching a decrease of 22 and $25 \%$, respectively, at the final harvest (Fig. 2d, e). Thuricin-17 application positively enhanced both traits over the water stress treatment, although they remained statistically lower than well-watered plants. Water deficit decreased plant biomass by 10 days after water stress imposition, but in this case, thuricin-17 treatment completely restored the plant biomass observed under well-watered conditions, by 16 days after treatment (Fig. 2f). Observations made in this study strengthen the hypothesis that interaction between thuricin-17 and Bradyrhizobium japonicum is a way to mitigate losses in soybean growth, normally occurring under water stress conditions. Indeed, the application of moderate water stress during soybean vegetative development, decreased plant biomass and leaf area, while a restoration of plant biomass occurred when thuricin-17 was applied under water stress conditions.

Leaf water potential was the first measured variable among aerial parts to respond to drought and to thuricin-17 application. Leaf water potential significantly decreased in waterstressed plants compared to the well-watered control even only 5 days after the beginning of water stress treatment, and a partial mitigation of thuricin-17 compared to the water-stressed plants occurred 10 days after the beginning of its application (Fig. 2a). Stomatal conductance and leaf photosynthetic rates were also strongly affected by water stress and were decreased to 32 and $15 \%$, respectively, compared to well-watered plants at the final harvest (Fig. 2b, c). The photosynthetic rate was improved by thuricin- 17 treatment of water-stressed plants, although not to the extent of restoring the levels observed in well-watered conditions.

Water stress induced modifications of the soybean root system architecture. It increased the root length of approximately $20 \%$ (Fig. 3b), and root diameter of $16 \%$ after 16 days of water stress (Fig. 3c). The number of root tips was unchanged by either soil water conditions or by thuricin-17 (Fig. 3d). A marked increase in root biomass was observed after thuricin- 17 application, as it was $37 \%$ higher than for the water-stressed plants (Fig. 3a), and this was associated with an increase of root length (Fig. 3b).
Water stress conditions strongly affected the production of nodules as their number was reduced by around $55 \%$ at the final harvest (Fig. 3e), and by $40 \%$ when the water stress was combined with thuricin-17. Moreover, a stagnation of nodule formation occurred between 10 and 15 days after water stress imposition, even if thuricin-17 was applied. However, even if nodule dry weight was decreased by water stress and thuricin17 conditions (by 50 and $48 \%$, respectively), nodule dry weight increased throughout plant development and among all treatments, indicating that nodule growth itself had not ceased (Fig. 3f). It was only the establishment of new nodules that had stopped.

This modification of the root/shoot ratio induced by thuricin-17 application illustrates an amplified adaptive strategy to local limiting conditions, commonly observed under water stress conditions (Nelson et al. 2004). More precisely, in our case, root/shoot ratio was improved by a limitation of energy costs consisting in a decrease of new root branching associated to an enhanced root elongation. The major consequence of such drought avoidance strategy in the presence of thuricin-17 was the increased water absorption by roots, leading to a better water state of the whole plant - as reflected by an enhancement of leaf water potential. Therefore, leaf elementary functions such as transpiration or photosynthesis were improved by thuricin-17. It has been well-established that a moderate water stress applied to soybean induces a decrease in photosynthesis due, in particular, to a decrease in $\mathrm{CO}_{2}$ diffusion from the atmosphere to the carboxylation site (Chaves and Oliveira 2004). Moreover, the reduced activity of Rubisco has been shown to be explained by conditions of low stomatal conductance and chloroplast $\mathrm{CO}_{2}$ concentration (Flexas et al. 2006). If thuricin-17 has already been shown to enhance soybean photosynthetic rate under conditions that were not assessed for stress level (Lee et al. 2009), to our knowledge, this is the first time it has been proven that a signalling molecule produced by a PGPR can alleviate the negative effect of water stress on carbon metabolism in soybean.

\subsection{Thuricin-17 enhanced $\mathrm{N}_{2}$-fixation and modified $\mathrm{N}$ partitioning among plant organs}

With regard to nitrogen acquisition, which was only based on $\mathrm{N}_{2}$ fixation in this study, water stress induced a large decrease in plant $\mathrm{N}$ fixation (around $30 \%$ less than under well-watered conditions) which was detectable by 16 days after drought imposition (Table 1). Water stress induced a reduction of nodule-specific activity (Table 1) and a decrease of nodule number by $55 \%$ (Fig. 2e), as previously reported (King and Purcell 2001; Serraj et al. 1999; Streeter 2003). This decrease was significantly mitigated by thuricin- 17 application, leading to a loss of fixed $\mathrm{N}$, corresponding to only $18 \%$ of the $\mathrm{N}$ fixed under well-watered conditions. In parallel, the specific activity 
Leaf water potential

(MPa)

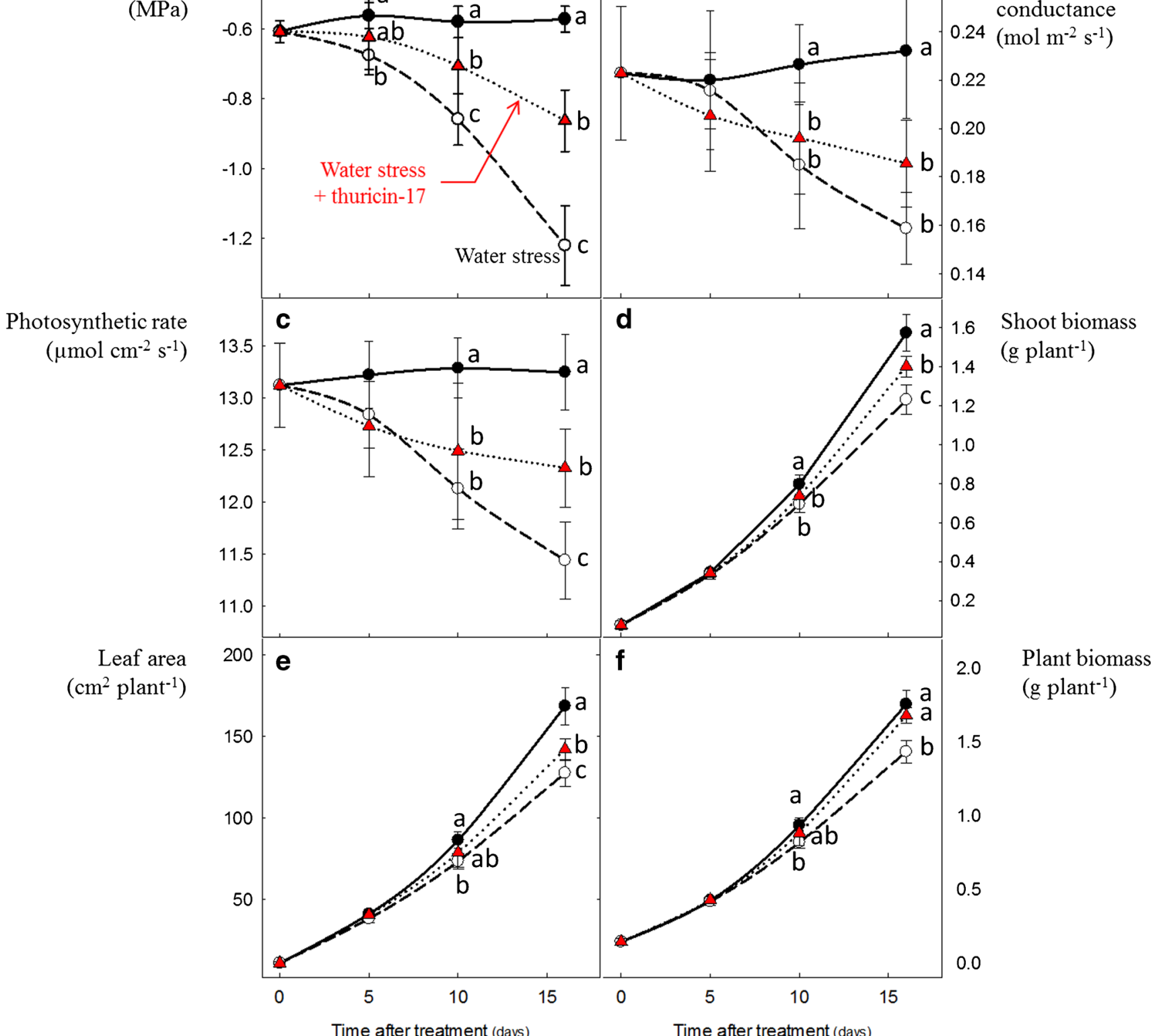

Fig. 2 Effect of well-watered conditions (black circles), water stress (white circles) and thuricin-17 application under water stress (triangles), during plant development on a leaf water potential, b stomatal conductance, $\mathbf{c}$ photosynthetic rate, $\mathbf{d}$ shoot biomass, e leaf area and $\mathbf{f}$ plant biomass. Each point represents mean \pm standard deviation $(n=10)$.

of nodules displayed a similar pattern in response to both treatments, as it was decreased by water stress conditions, and the decline was slightly alleviated by thuricin- 17 .

Under well-watered conditions, Lee et al. (2009) have shown that root application of thuricin-17 in interaction with Bradyrhizobium japonicum led to increase soybean nodule number but not the nodule growth. In our study, under water stress conditions, thuricin-17 induced an activation of nodule formation only during the first 10 days of treatment, a partial restoration of nodule-specific activity, a partial restoration of
Differences among treatments significant at the 0.05 probability level are denoted by different letters on the bars. Thuricin-17 application under water stress condition enhanced above-ground growth and photosynthetic activity when compared with the water stress-alone condition

nodule growth and consequently, an increase of the total $\mathrm{N}$ quantity in the plant (Table 1 and Fig. 3). The activation of nodule formation during the first 10 days of thuricin- 17 treatment can be explained as an adjustment of $\mathrm{N}$ supply to the demand reflected by the shoot biomass: at 10 days after treatment imposition, both shoot biomass and nodule number were lower than for the well-watered plants (Figs. 2d and 3e). These observations were in accordance with a study showing that the nodulation process in pea is tightly attuned to plant growth (Voisin et al. 2010). Moreover, this adaptive strategy 


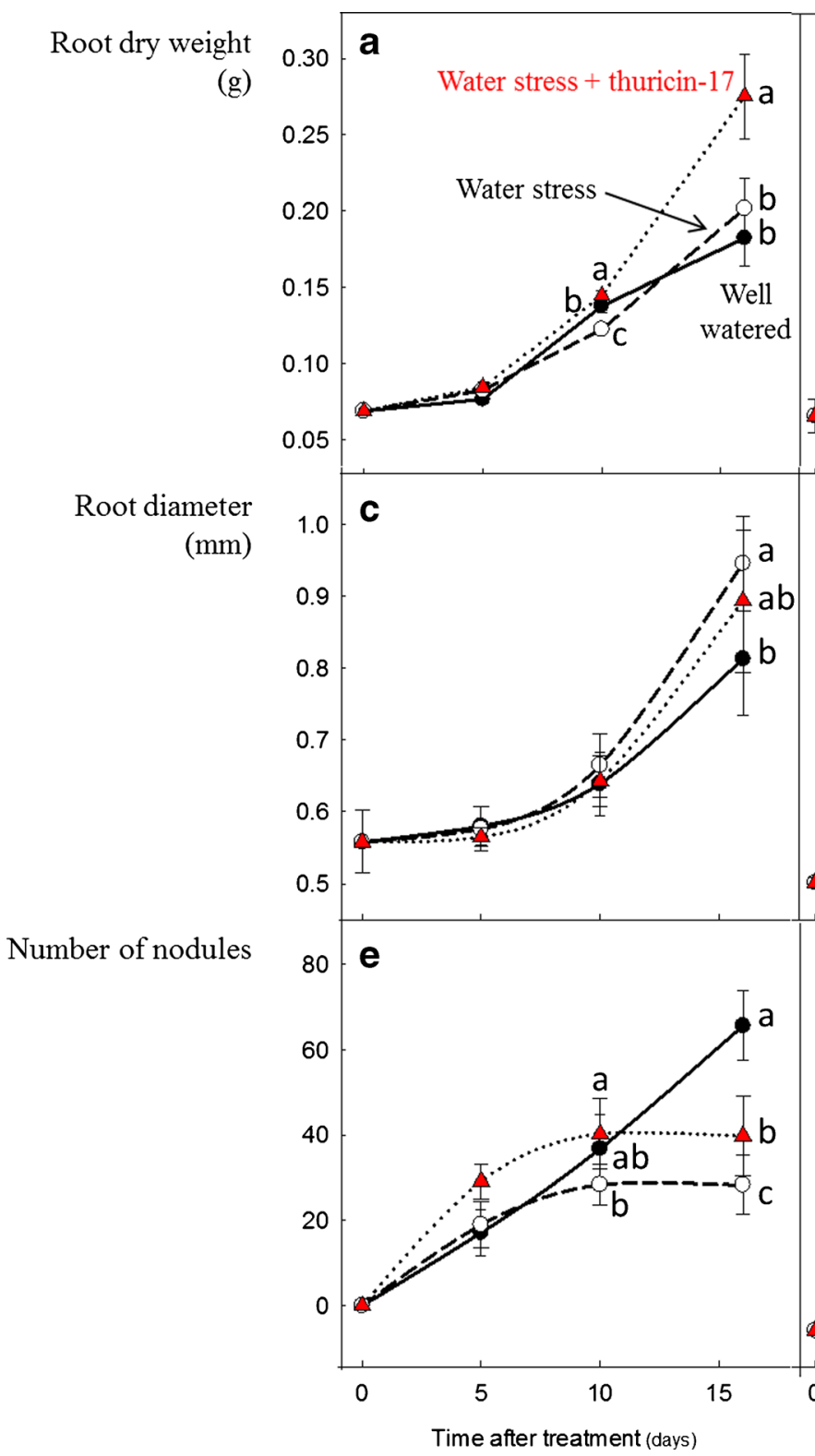

Fig. 3 Effect of well-watered conditions (black circles), water stress (white circles) and thuricin-17 application under water stress (triangles), during plant development on a root dry weight, $\mathbf{b}$ root length, $\mathbf{c}$ root diameter, $\mathbf{d}$ number of root tips, $\mathbf{e}$ number of nodules and $\mathbf{f}$ nodule dry weight. Each point represents mean \pm standard deviation $(n=10)$. Differences among treatments significant at the 0.05 probability level, are b

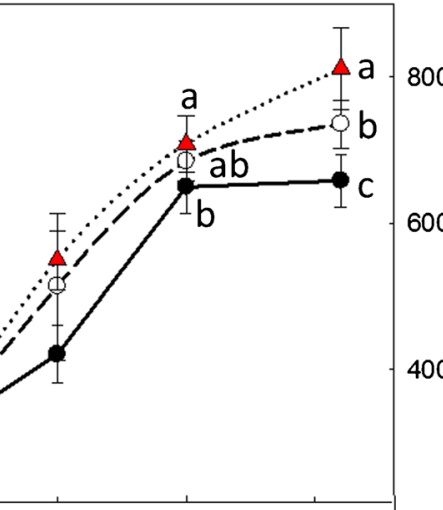

d
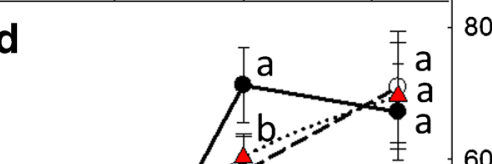

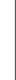

Number of root tips

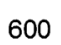

Root length

$(\mathrm{cm})$

000

400

600

400

200

Nodule dry weight (g)
Table 1 Effect of well-watered conditions, water stress and thuricin-17 application under water stress on $\mathrm{N}$ concentration within the different plant organs, on $\mathrm{N}_{2}$-fixation and on the specific activity of the nodules at the final harvest (16 days after treatment). Differences among treatments significant at the 0.05 probability level, are denoted by different letters

\begin{tabular}{|c|c|c|c|c|c|c|}
\hline \multirow[b]{2}{*}{ Treatment } & \multicolumn{4}{|c|}{$\mathrm{N}$ concentration (mg g $\left.{ }^{-1} \mathrm{DW}\right)$} & \multirow{2}{*}{$\begin{array}{l}\text { Fixed } N \\
\left(\mathrm{mg} \mathrm{plant}^{-1}\right)\end{array}$} & \multirow{2}{*}{$\begin{array}{l}\text { Specific activity of nodules } \\
\left(\mathrm{g} \mathrm{N}[\mathrm{g} \operatorname{nod} \mathrm{DW}]^{-1} \mathrm{~d}^{-1}\right)\end{array}$} \\
\hline & Leaf & Root & Stem & Nodules & & \\
\hline Well-watered control & $29.5 \mathrm{a}$ & $21.8 \mathrm{a}$ & $21.8 \mathrm{a}$ & $58.6 \mathrm{a}$ & $49.9 \mathrm{a}$ & $0.040 \mathrm{a}$ \\
\hline Water stress & $29.4 \mathrm{a}$ & $23.1 \mathrm{a}$ & $13.7 \mathrm{~b}$ & $56.2 \mathrm{~b}$ & $34.7 \mathrm{c}$ & $0.022 \mathrm{c}$ \\
\hline Water stress combined with thuricin-17 & $28.4 \mathrm{a}$ & $21.2 \mathrm{a}$ & $14.7 \mathrm{~b}$ & $54.7 \mathrm{~b}$ & $40.6 \mathrm{~b}$ & $0.029 \mathrm{~b}$ \\
\hline
\end{tabular}


Fig. 4 a Percentage of nitrogen (N) contained in the various plant organs (leaves, stem, nodules and roots), at final harvest (16 days after treatment). b Percentage of dry mass contained in the various plant organs (leaves, stem, nodules and roots). Each column represents the mean of $n=10$ plants. For each organ, LSD tests were used to evaluate the differences among treatments. Differences among treatments significant at the 0.05 probability level are denoted by different letters on the columns. A higher proportion of $\mathrm{N}$ was allocated to the below-ground structures under water stress conditions (combined or not with thuricin17), which can be interpreted as the direct consequence of changes in biomass partitioning (belowground organs had a higher biomass allocation under water stress than under well-watered conditions) a

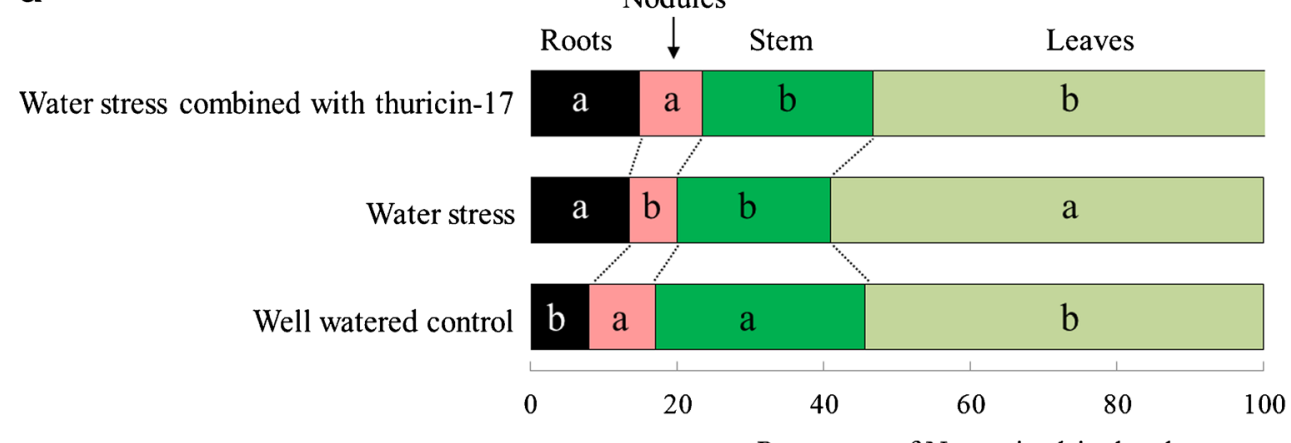

Percentage of $\mathrm{N}$ contained in the plant organ, in relation to the plant total $\mathrm{N}$ content

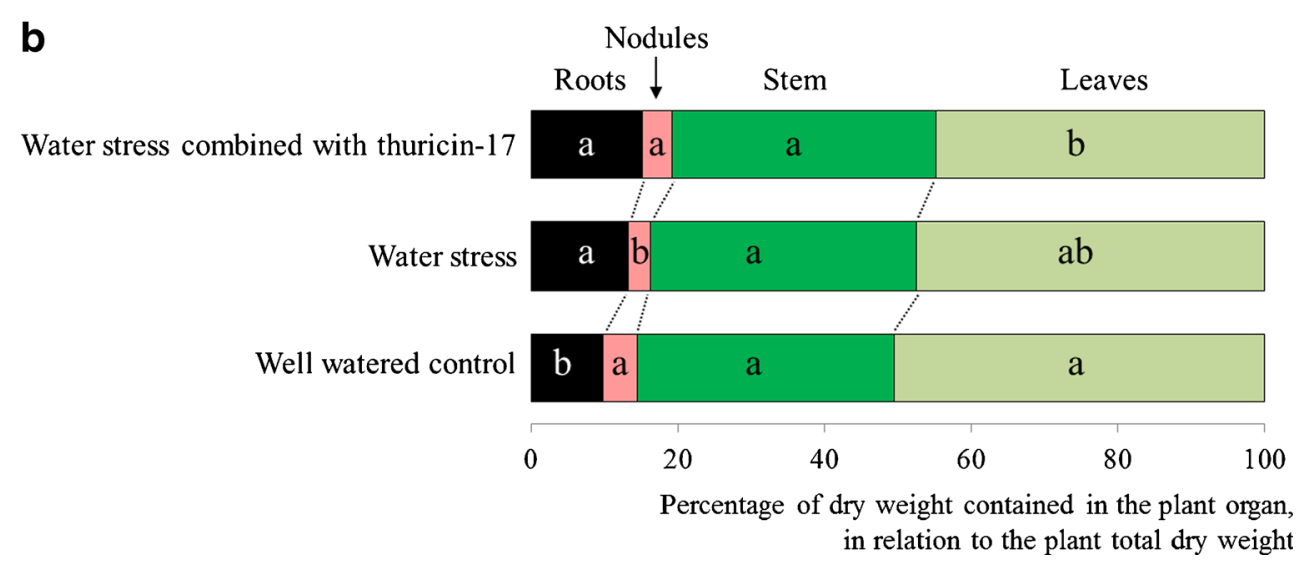

consisting in enlarging pre-existing structures, instead of producing new structures, can be interpreted as a way to optimize energy costs under water stress conditions.

Despite the enhancement of $\mathrm{N}$ acquisition by thuricin- 17 application under water stress, $\mathrm{N}$ concentration in shoots was not modified by thuricin-17 (Table 1 and Fig. 4), confirming that the enhancement of photosynthesis after thuricin-17 application was not due to an increase of leaf $\mathrm{N}$ concentration. On the other hand, and contrary to what occurs in pea, where $\mathrm{N}$ partitioning between below-ground and above-ground tissues is not modified by water stress (Mahieu et al. 2009), soybean $\mathrm{N}$ partitioning among the various plant organs was
Leaf ABA concentration ( $\left.\mathrm{nmol} \mathrm{g}{ }^{-1} \mathrm{DW}\right)$

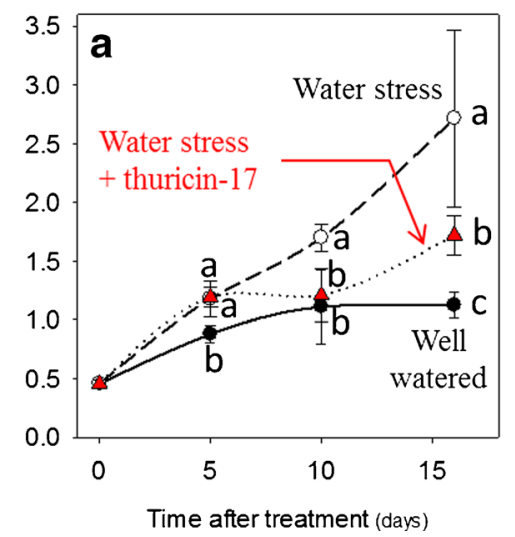

Fig. 5 Effect of well-watered conditions (black circles), water stress (white circles) and thuricin-17 application under water stress (triangles), during plant development on a leaf abscisic acid (ABA) concentration, b root ABA concentration, and $\mathbf{c}$ nodule $\mathrm{ABA}$ concentration. Each point represents mean \pm standard deviation $(n=3$ biological pools composed by 2-3 plants). Differences among treatments at each time point significant
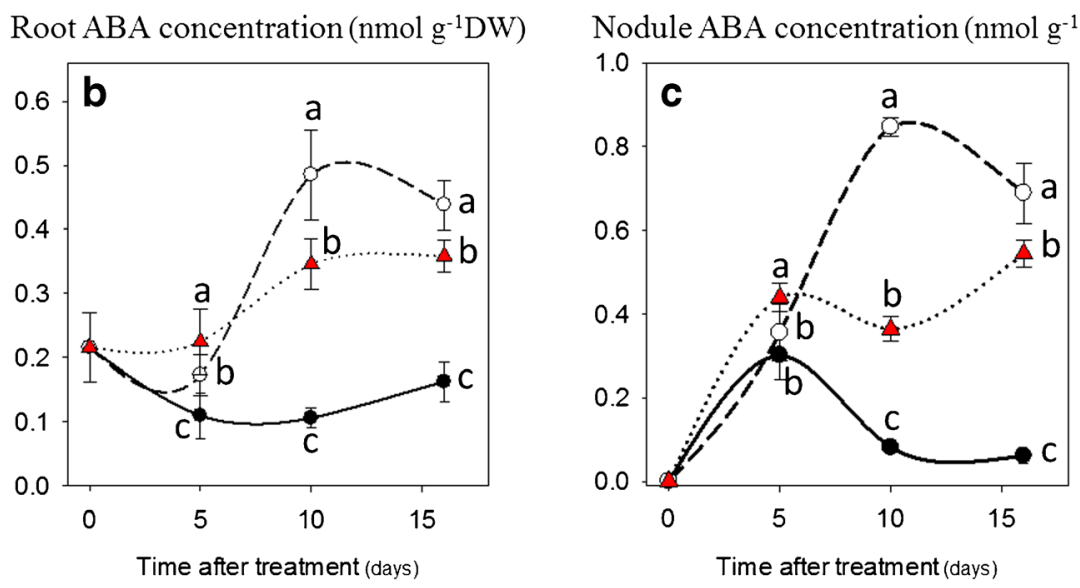

at the 0.05 probability level are indicated by different letters on the points. When thuricin-17 was applied to water-stressed plants, the concentration of ABA in roots and in nodules was higher than under water stress-alone conditions at 5 days after treatment, corresponding to the earliest response, which was observed 
affected by water stress conditions and thuricin-17 application: both treatments induced a higher proportion of $\mathrm{N}$ allocation to the below-ground structures. Taken together, these results suggested that changes observed for $\mathrm{N}$ partitioning are the direct consequence of changes in biomass partitioning: less $\mathrm{N}$ is used in the photosynthetic pathway of shoot tissues, another adaptive strategy to stress conditions (Poorter and Nagel 2000).

\subsection{Thuricin-17 affected abscisic acid synthesis under water} stress

The earliest signal which has been observed after thuricin-17 application was the increase of the abscisic acid (ABA) content in leaves and roots (Fig. 5), and the differences between plants grown under well-watered and water-stressed conditions were amplified throughout their development. When thuricin-17 was applied to water-stressed plants, the concentration of ABA in roots and in nodules was even higher than under water stress-alone conditions at 5 days after treatment. Subsequently, ABA concentrations of plants treated with thuricin-17 were moderated and ranged intermediately between well-watered and water-stressed plants, for all the plant organs (leaves, roots or nodules).

This hormone is known as a plant sensor for soil water availability in the rhizosphere, which is produced in the roots, transported in the xylem by way of the transpiration stream, and induces a transduction cascade in the leaves involving $\mathrm{Ca}^{2+}, \mathrm{K}^{+}$and $\mathrm{Cl}^{-}$adjustments, which leads to stomatal closure, a reduction of water loss from leaves, and an inhibition of shoot growth (Davies and Zhang 1991; Jones and Mansfield 1970), as well as the maintenance of root elongation by restricting ethylene production (Spollen et al. 2000). This suggests that the change in plant hormonal balance (from the roots) could be one causal element leading to modifications of root elongation. Indeed, when treated with thuricin17, plant adjustment of ABA concentration led to a maximal root growth explained by the elongation of the pre-existing roots, and consequently led to a better water uptake.

\section{Conclusion}

Thus, it has been demonstrated that thuricin-17 enhanced plant tolerance to water stress by amplifying the adaptive strategy which is commonly deployed under water-limiting conditions: by (i) modifications of $\mathrm{C}$ and $\mathrm{N}$ acquisition and allocation among the different plant organs, (ii) changes in activities of these components $\left(\mathrm{N}_{2}\right.$-fixation, photosynthesis, transpiration...). To explain our results, we propose a mechanism involving thuricin-17 as a modulator of plant hormonal balance, being the causal element leading to modifications of root elongation, allowing a better water uptake, a better water state of the plant and thus enhancing the main functions related to carbon and nitrogen acquisition.

Acknowledgments We are grateful to Sophie Baubil for taking care of the plants and for her assistance during harvests and to Anne-Lise Santoni for carbon and nitrogen analyses. We would like to thank Amy Galer for the technical support with hormone extraction and Leonid Kurepin, Allison Hayward and Heather Francis for their help with the mass spectrometer.

\section{References}

Acharya B, Assmann S (2009) Hormone interactions in stomatal function. Plant Mol Biol 69:451-462. doi:10.1007/s11103-008-9427-0

Avice JC, Larmure A, Ourry A, Prudent M, Voisin AS and Salon C (2011) Plant $\mathrm{N}$ fluxes and modulation by nitrogen, heat and water stresses: a review based on comparison of legumes and non legume plants. In Abiotic Stress in Plants: Mechanisms and Adaptations Eds. A Shanker and B Venkateswarlu. INTECH. doi: 10.5772/23474

Bai Y, D'Aoust F, Smith DL, Driscoll BT (2002) Isolation of plant growth promoting Bacillus strains from soybean nodules. Can J Microbiol 48:230-238. doi:10.1139/w02-014

Bresson J, Varoquaux F, Bontpart T, Touraine B, Vile D (2013) The PGPR strain Phyllobacterium brassicacearum STM196 induces a reproductive delay and physiological changes that result in improved drought tolerance in Arabidopsis. New Phytol 200:558569. doi:10.1111/nph.12383

Chaves MM, Oliveira MM (2004) Mechanisms underlying plant resilience to water deficits: prospects for water-saving agriculture. J Exp Bot 55:2365-2384. doi:10.1093/jxb/erh269

Davies WJ, Zhang JH (1991) Root signals and the regulation of growth and development of plants in drying soil. Annu Rev Plant Physiol Plant Mol Biol 42:55-76. doi:10.1146/annurev.pp. 42.060191. 000415

Dodd IC, Zinovkina NY, Safronova VI, Belimov AA (2010) Rhizobacterial mediation of plant hormone status. Ann Appl Biol 157:361-379. doi:10.1111/j.1744-7348.2010.00439.x

Easterling WE, Aggarwal PK, Batima P, Brander KM, Erda L, Howden SM, Kirilenko A, Morton J, Soussana JF, Schmidhuber J, Tubiello FN (2007) Food, fibre and forest products. Climate change 2007: impacts, adaptation and vulnerability. In: Parry ML, Canziani OF, Palutikof JP, van der Linden PJ, Hanson CE (eds) Contribution of Working Group II to the Fourth Assessment Report of the Intergovernmental Panel on Climate Change. Cambridge University Press, Cambridge, UK, pp 273-313

Flexas J, Ribas-Carbo M, Bota J, Galmes J, Henkle M, Martinez-Canellas S, Medrano H (2006) Decreased rubisco activity during water stress is not induced by decreased relative water content but related to conditions of low stomatal conductance and chloroplast $\mathrm{CO}_{2}$ concentration. New Phytol 172:73-82. doi:10.1111/j.1469-8137.2006. 01794.x

Friedman M, Brandon DL (2001) Nutritional and health benefits of soy proteins. J Agric Food Chem 49:1069-1086. doi:10.1021/ jf0009246

Friesen ML, Porter SS, Stark SC, von Wettberg EJ, Sachs JL, MartinezRomero E (2011) Microbially mediated plant functional traits. Annu Rev Ecol Evol Syst 42:23-46. doi:10.1146/annurev-ecolsys102710-145039

Goh CH, Veliz Vallejos DF, Nicotra AB, Mathesius U (2013) The impact of beneficial plant-associated microbes on plant phenotypic plasticity. J Chem Ecol 39:826-839. doi:10.1007/s10886-013-0326-8 
Gray EJ, Lee KD, Souleimanov AM, Di Falco MR, Zhou X, Ly A, Charles TC, Driscoll BT, Smith DL (2006) A novel bacteriocin, thuricin 17, produced by plant growth promoting rhizobacteria strain Bacillus thuringiensis NEB17: isolation and classification. J Appl Microbiol 100:545-554. doi:10.1111/j.1365-2672.2006.02822.x

Jones RJ, Mansfield TA (1970) Suppression of stomatal opening in leaves treated with abscisic acid. J Exp Bot 21:714-719. doi:10.1093/jxb/ 21.3.714

King CA, Purcell LC (2001) Soybean nodule size and relationship to nitrogen fixation response to water deficit. Crop Sci 41:1099-1107. doi:10.2135/cropsci2001.4141099x

Lee K, Gray E, Mabood F, Jung WJ, Charles T, Clark S, Ly A, Souleimanov A, Zhou X, Smith D (2009) The class IId bacteriocin thuricin-17 increases plant growth. Planta 229:747-755. doi:10. 1007/s00425-008-0870-6

Liu FL, Andersen MN, Jacobsen SE, Jensen CR (2005) Stomatal control and water use efficiency of soybean (Glycine max L. Merr.) during progressive soil drying. Environ Exp Bot 54:33-40. doi:10.1016/j. envexpbot.2004.05.002

Mahieu S, Germon F, Aveline A, Hauggaard-Nielsen H, Ambus P, Jensen ES (2009) The influence of water stress on biomass and $\mathrm{N}$ accumulation, $\mathrm{N}$ partitioning between above and below ground parts and on $\mathrm{N}$ rhizodeposition during reproductive growth of pea (Pisum sativum L.). Soil Biol Biochem 41:380-387. doi:10.1016/j.soilbio.2008.11.021

Manavalan LP, Guttikonda SK, Tran LSP, Nguyen HT (2009) Physiological and molecular approaches to improve drought resistance in soybean. Plant Cell Physiol 50:1260-1276. doi:10.1093/ $\mathrm{pcp} / \mathrm{pcp} 082$

Nelson JA, Morgan JA, LeCain DR, Mosier A, Milchunas DG, Parton BA (2004) Elevated CO2 increases soil moisture and enhances plant water relations in a long-term field study in semi-arid shortgrass steppe of Colorado. Plant Soil 259:169-179. doi:10.1023/B:PLSO. 0000020957.83641 .62

Poorter H, Nagel O (2000) The role of biomass allocation in the growth response of plants to different levels of light, $\mathrm{CO}_{2}$, nutrient and water: a quantitative review. Aust J Plant Physiol 27:595-607. doi: 10.1071/PP99173 CO
Ross ARS, Ambrose SJ, Cutler AJ, Feurtado JA, Kermode AR, Nelson K, Zhou R, Abrams SR (2004) Determination of endogenous and supplied deuterated abscisic acid in plant tissues by highperformance liquid chromatography-electro-spray ionization tandem mass spectrometry with multiple reaction monitoring. Anal Biochem 329:324-333. doi:10.1016/j.ab.2004.02.026

Schuize J, Adgo E, Merbach W (1999) Carbon costs associated with $\mathrm{N}_{2}$ fixation in Vicia faba L. and Pisum sativum L. over a 14-day period. Plant Biol 1:625-631. doi:10.1111/j.1438-8677.1999.tb00273.x

Serraj R, Sinclair TR, Purcell LC (1999) Symbiotic $\mathrm{N}_{2}$ fixation response to drought. J Exp Bot 50:143-155. doi:10.1093/jxb/ 50.331 .143

Spollen WG, LeNoble ME, Samuels TD, Bernstein N, Sharp RE (2000) Abscisic acid accumulation maintains Maize primary root elongation at low water potentials by restricting ethylene production. Plant Physiol 122:967-976. doi:10.1104/pp. 122.3.967

Streeter JG (2003) Effects of drought on nitrogen fixation in soybean root nodules. Plant Cell Environ 26:1199-1204. doi:10.1046/j.13653040.2003.01041.x

Vadez V, Berger JD, Warkentin T, Asseng S, Ratnakumar P, Rao KPC, Gaur PM, Munier-Jolain N, Larmure A, Voisin AS, Sharma HC, Pande S, Sharma M, Krishnamurthy L, Zaman MA (2011) Adaptation of grain legumes to climate change: a review. Agron Sustain Dev 32:31-44. doi:10.1007/s13593-011-0020-6

Voisin AS, Munier-Jolain NG, Salon C (2010) The nodulation process is tightly adjusted to plant growth. An analysis using environmentally and genetically induced variation of nodule number and biomass in pea. Plant Soil 337:399-412. doi:10.1007/s11104010-0536-6

Wallace JS (2000) Increasing agricultural water use efficiency to meet future food production. Agric Ecosyst Environ 82:105-119. doi:10. 1016/S0167-8809(00)00220-6

Whipps JM (2001) Microbial interactions and biocontrol in the rhizosphere. J Exp Bot 52:487-511. doi:10.1093/jexbot/52.suppl_1.487

Yang J, Kloepper JW, Ryu CM (2009) Rhizosphere bacteria help plants tolerate abiotic stress. Trends Plant Sci 14:1-4. doi:10.1016/j. tplants.2008.10.004 